\title{
STUDY ON OUTCOME OF ECLAMPSIA PATIENTS IN DISTRICT HOSPITAL IN BANGLADESH
}

\author{
TAHMINA HZ ${ }^{1}$, SHAHID AR ${ }^{2}$, HOSNA AU $^{3}$, ALAM A ${ }^{4}$
}

\begin{abstract}
The study was carried out to evaluate the fate and outcome of eclampsia patients and their neonates. This hospital based prospective study was done in Chuadanga Sadar Hospital, a 100 bed secondary health care centre in Chuadanga district in Bangladesh, from January 2007 to December 2009. The number of study population was 50, which include antepartum, intrapartum and postpartum eclampsia. Among them, $70 \%$ had spontaneous vaginal delivery, $10 \%$ had assisted vaginal delivery and 10\% had caesarian section. $86 \%$ of the patient have good maternal outcome with the use of anti convulsant therapy. 46\% of baby of total population have good neonatal outcome with or without immediate resuscitation. The outcome of eclampsia is satisfactory if immediate treatment is started. Hence, every patient should be admitted in hospital as soon as possible and receive anticonvulsant therapy immediately, even before admission in hospital. Patient should be delivered with special care as a high risk mother and neonatal support should be given to reduce both maternal and neonatal mortality and morbidity.
\end{abstract}

Key words: Eclampsia, preeclampsia, maternal mortality.

J Dhaka Med Coll. 2014; 23(2) : 223-226.

\section{Introduction}

Eclampsia is best regarded as a complication of hypertensive disorder of pregnancy. While most pregnancies and birth are uneventful, all pregnancies are at risk. Eclampsia is a life threating obstetric complication. ${ }^{1,2}$ It is the occurrence of convusion in association with the feature of pre eclampsia. It is an emergency situation, requiring immediate diagnosis and management. It is characterized by hypertension, proteinuria and convulsion with unknown etiology. ${ }^{3,4,5}$ Eclampsia is an important cause of maternal mortality. Infact most of the cases there are warning sign and they are through pre eclamptic stage of hypertension. In most of the cases the outcomes of delivery depend on frequency, duration and number of convulsion, gestational age, parity and age of the patient. Around $15 \%$ of all pregnant women develop a potentially life threating complication and requires emergency skilled and obstetric care. ${ }^{8,10}$ The world wide incidence of preeclampsia is still high inspite of the significant improvement of the maternal and child care over the last decades. All over the world pre eclampsia is the $3^{\text {rd }}$ lead-ing cause for maternal mortality and the $7^{\text {th }}$ leading cause for the perinatal mortality. ${ }^{3}$ The present study was carried out to evaluate the fate and outcome of eclampsia patients and their neonates in ac secondary district level hospital set up in Bangladesh.

\section{Methods}

This hospital based prospective study was done in Obstetric unit of Chuadanga 100 Bedded Sadar Hospital, Chuadanga, in collaboration with Department of Pediatrics of the same hospital. 50 patients were admitted with eclampsia or developed convulsion after admission and delivery. Among them 7 had pre eclampsia or PIH and convulsion developed after delivery. Eclampsia with other medical

1. Dr. Hosna Zari Tahmina, Consultant, Obstetrics \& Gynaecology, Chuadanga Sadar Hospital, Chuadanga.

2. Dr. Asma Rumanaz Shahid, Lecturer, Department of Anatomy, Dhaka Medical College, Dhaka.

3. Dr. Asma U1 Hosna, Assistant Professor, Department of Obstetrics \& Gynaecology, Bangabandhu Sheikh Mujib Medical University (BSMMU), Dhaka.

4. Dr. Ashraful Alam, Department of Obstetrics \& Gynaecology, Bangabandhu Sheikh Mujib Medical University (BSMMU), Dhaka.

Correspondence: Dr. Asma Rumanaz Shahid, Lecturer, Department of Anatomy, Dhaka Medical College, Dhaka. Cell Phone: +8801711544132. 
complications as heart disease, kidney disease or diabetes were excluded from the study.

\section{Results}

Among them, $70 \%$ had spontaneous vaginal delivery, $10 \%$ had assisted vaginal delivery and $10 \%$ had caesarian section. $86 \%$ of the patient have good maternal outcome with the use of anti convulsant therapy. $46 \%$ of baby of total population have good neonatal outcome with or without immediate resuscitation. The results are shown in the following tables.

Table-I

Distribution of patients according to the type of eclapmsia.

\begin{tabular}{lcc}
\hline Type & No. of cases & Percentage \\
\hline 1. Antepartum & 41 & $82 \%$ \\
2. Intrapartum & 5 & $10 \%$ \\
3. Postpartum & 4 & $8 \%$ \\
\hline
\end{tabular}

Table-II

Distribution of patients according to mode of delivery.

\begin{tabular}{lcc}
\hline Type & No. of cases & Percentage \\
\hline $\begin{array}{l}\text { 1. Spontaneous } \\
\text { 2. Assisted vaginal delivery } \\
\text { (Forcep/ventose) }\end{array}$ & 5 & $70 \%$ \\
\begin{tabular}{l} 
3. LUCS \\
\hline
\end{tabular} & 5 & $10 \%$ \\
\hline
\end{tabular}

Table-III

Distribution of patients according to maternal outcome

\begin{tabular}{|c|c|c|}
\hline Type & o. of cases & Percentage \\
\hline $\begin{array}{l}\text { I. Good maternal outcome } \\
\text { (with use of Magsulph, } \\
\text { diazepam) }\end{array}$ & 43 & $86 \%$ \\
\hline $\begin{array}{l}\text { II. Poor maternal outcome } \\
\text { (death due to multiorgan } \\
\text { failure) }\end{array}$ & $\ln 3$ & $6 \%$ \\
\hline
\end{tabular}

Table-IV

Distribution of the patients according to the time of onset of treatment

\begin{tabular}{llc}
\hline No. of cases & Time of onset of treatment & Percentage \\
\hline 38 & Immediate within 6 hours of treatment & 35-good (70\%) \\
12 & Delayed after 6 hours & 4-poor (8\%) \\
\hline
\end{tabular}

Table-V

Distribution of patients according to neonatal outcome

\begin{tabular}{llcc}
\hline Type & No. of cases & Percentage \\
\hline I. $\quad$ Good neonatal outcome (neonates without any complications & & \\
with or without resuscitation) & 23 & $46 \%$ \\
II. $\quad$ Poor neonatal outcome & 27 & $54 \%$ \\
& a. IUD & 9 & $18 \%$ \\
b. Neonatal complications & 18 & $36 \%$ \\
$\quad$ Prematurity & & \\
$\quad$ Infection & & \\
$\quad$ RDS &
\end{tabular}

\section{Discussion}

Eclampsia is the second common cause of maternal death after PPH. Eclampsia account for about $16 \%$ of maternal death in Bangladesh. Mortality from hypertensive disorders is much higher in developing countries. The pathophysiology is thought to be cerebral vasospasm leading to ischaemia and cerebral oedema. World wide cerebral haemorrhage is the principal cause of death, although pulmonary complications have now superseded cerebral cause. Lack of antenatal care or substandard care is related to death in hypertensive diseases. $3,4,5$ 
Eclamptic seizure classically occurs in the second half of pregnancy and upto 10 days after delivery. They are tonic-clonic in type being followed by a brief period of coma. Many women manifest excitability or hyper reflexia prior to the onset of seizure. The diagnosis is certain when convulsion occur in women with pre eclampsia, while $20 \%$ of women with eclampsia are normotensive and $30 \%$ have no premonitory proteinuria. ${ }^{8,9}$ Hypertension and proteinuria in 2 nd half of pregnancy is called pre eclampsia. However $38 \%$ do not have established proteinuria and hypertension before the first fit and less than 60\% have antecedent symptoms. The diagnosis and treatment are more difficult if a woman is found unconscious. ${ }^{1,2,3}$ Hoiwever, persistent coma or development of localize sign should raise the possibility of cerebral accident. Pregnancy induced hypertension (PIH) occur in around 16 to $24 \%$ in first pregnancy and 12 to $15 \%$ of subsequent pregnancies, with around 5 to $10 \%$ of cases being developed eclampsia. ${ }^{3,4}$ Its incidence in UK is 4.9 of 100,000 deliveries. The maternal case fatality rate is $1.8 \%$ and $15 \%$ of women will have at least one major complication (Douglas and Redman 1994) like seizure; $38 \%$ of that occur during antepartum , $18 \%$ in intrapartum and $44 \%$ occur in postpartum period. ${ }^{3,4,5}$

In Bangladesh, the incidence of pre eclampsia is very high. It is about $10 \%$ to $15 \%$ of all deliveries. ${ }^{8}$ In this country only $49 \%$ of women of total population is under antenatal care and only 30\% women are aware of pregnancy complication during pregnancy. 13\% women end their pregnancies under medical supervision and the rest of them have delivery assistance from TBA, relatives and friends or no access to obstetric care. ${ }^{14}$ Only $29 \%$ of women get treatment for complication from medically trained provider ${ }^{15}$. As a result most pre eclampsia cases remain unrecognized until severe complication such as eclamp-sia occurs. Pre eclampsia is the leading cause of prema-ture termination of pregnacy, and so as intrauterine growth retardation,,perinatal mortality and morbidity. Eclampsia is a preventable disease if pre eclampsia is detected and treated at an early stage. ${ }^{11,12}$
The most important factor determining the fetal outcome is gestational age at the time of delivery. Survival rate increases when delivery occurred after 35 week gestation. Mortality is increased two fold if the fetus is small for gestational age. ${ }^{10,11}$ Although in developed countries there has been significant improvement in the outcome of hypertension in pregnancies, due to better blood pressure control before, during and after pregnancy, vigorous antenatal, intranatal and postnatal care. The management in our country still posses a major challenge. ${ }^{7,8}$

In this study, the total number of patients was 50. Among them, 41 had antepartum, 5 had intrapartum and 4 had postpartum eclampsia.. Among the antepartum eclamptic patients, $70 \%$ had spontaneous vaginal delivery, $10 \%$ had assisted vaginal delivery, 10\% delivered by LUCS and rest was referred to tertiary center for management of different complications. Among 46 patients, 22 patients had spontaneous labour within 24 hour of admission. Induction was done in 21 patients by artificial rupture of membrane and oxytocin drip. LUCS was done in 5 cases after controlling of fit for failed induction, severe oligohydramnios etc. Among 50 patients of the study population 3 died after admission, 2 of them had postpartum and 1 had antepartum eclapmsia. All of them were admitted with deep unconsciousness and frank haematuria. The cause of death was thought to be multiorgan failure. One patient with frank haematuria and deep unconsciousness and 4 with status eclampticus were referred to tertiary center.

Among 50 patients, 38 (with antepartum, intrapartum and postpartum eclampsia) received anticonvulsant $\left(\mathrm{MgSo}_{4}\right)$ treatment within 6 hours of onset of first fit. $70 \%$ of them showed good response to the treatment, but 3 of them did not respond well to the treatment and developed complications. 12 patients came late to the hospital, 6 hour after onset of first fit and received delayed treatment. But after receiving treatment 8 of them respond well to treatment 4 of them showed poor or no response to the treatment. 
$46 \%$ of the babies of total population had good neonatal outcome with or without immediate resuscitation. Ultimately $90 \%$ of them were discharged from hospital without any visible complication and 10\% developed RDS and needed admission in neonatal ward. 54\% of the babies of total population had poor outcome like IUD, prematurity and neonatal asphyxia. Among the 43 deliveries of good maternal outcome 2 neonates died in neonatal period and 41 discharged from hospital without significant complications.

\section{Conclusion}

Eclampsia is one of the important causes of maternal mortality. Most of the death can be prevented by regular antenatal checkup, early diagnosis of PIH, pre eclampsia and also extra monitoring and segregation of high risk mother. Outcome of eclampsia is also satisfactory if immediate treatment is started. So every patient should be admitted in hospital as soon as possible and receive anticonvulsant therapy immediately, even before admission in hospital. Patient should be delivered with special care as a high risk mother and neonatal support should be given to reduce both maternal and neonatal mortality and morbidity.

Screening should be done during antenatal care. All hypertensive patient should be identified and marked as high risk mother who are prone to develop eclampsia. Blood pressure should be maintained at base line level to minimize the development of eclampsia. All eclampsia patient must receive anticonvulsant therapy as early as possible.

\section{References:}

1. Damien, S, Patgric, G, Francies, P, Pierre, L, Serge, B, Gerad, B, et al. Aspirin (100mg) used for prevention of preeclampsia in nulliparous women, the Eassai Regional Aspirin Mere Enfant Study (Part-1). Br J Obstet Gynaecol 2003; 110: 475-84.
2. Dekker GA, Sibai BM. Primary, secondary and tertiary prevention of preeclampsia. Lancet 2001; 357: 209-15.

3. Dekker GA, Sibai, BM. Early detection of preeclampsia. Am J Obstet Gynecol 1991; 165: 160-72.

4. Philip JS, Mark PL, Tina KJ, Chapple. Maternal blood pressure in pregnancy, birth weight and perinatal mortality is first birth. BMJ 2004; 329: 1312-4.

5. Reynold C, Mabie WC, Sibai BM, Decherny AH, Nathan, L. Hypertensive status of pregnancy. $9^{\text {th }}$ ed. New York: McGraw-Hill; 2003: p.338-53.

6. Hall, DR, Odendaal, HJ, Steyn, DW, Grove, D. Expectant management of early onset severe preeclampsia: Maternal outcome. Br J Obstet Gynaecol 2000; 107: 1252-57.

7. Kieler, H, Zettergren, T, Svenson, H, Dickman, PW, Larsson, A. The renal pathology of toxemic of pregnancy. 2003, 12-17.

8. Khatoon MS. Clinical profile and management of eclampsia in SSMCH and MF, Dhaka. [Dissertation]. Dhaka: BCPS; 1992.

9. Kuo, VS, RM, Koumantakis, G, and Eileen, DM, Gallery. Proteinuria and its assessment in normal and hypertensive pregnancy. Am J Obstet Gynecol 1992; 167: 723-8.

10. Lucky C, Chappell MB, Paul T, Brily A, Kelly JF, Beverly $J$, et al. A longitudinal study of biochemical variables in women at risk of preeclampsia. Am J Obstet Gynecol 2002; 187: 127-36.

11. Redman CWG, Roberts, JM. Management of preeclampsia. Lancet 1993; 341: 1451-54.

12. Reynold C, Mabie WC, Sibai BM, Decherny AH, Nathan L. Hypertensive states of pregnancy. $9^{\text {th }}$ ed. New York: McGraw-Hill; 2003: p.338-53.

13. Roberts JM, Cooper DW. Pathogenesis and genetics of preeclampsia. Lancet 2001; 357 : 53-56.

14. Robers JM, Redman CWG. Preeclampsia: more than pregnancy induced hypertension. Lancet 1993; 341: 1447-51.

15. Statistics from The State of the World's Children 2007, BDHS and MICS. 